\title{
Tracing change in female genital mutilation/cutting: Shifting norms and practices among communities in Narok and Kisii counties, Kenya-Brief
}

Dennis Matanda

Population Council

Chantalle Okondo

Population Council

Caroline W. Kabiru

Population Council

Bettina Shell-Duncan

Follow this and additional works at: https://knowledgecommons.popcouncil.org/departments_sbsr-rh

Part of the Demography, Population, and Ecology Commons, Family, Life Course, and Society

Commons, Gender and Sexuality Commons, and the International Public Health Commons

How does access to this work benefit you? Let us know!

\section{Recommended Citation}

Matanda, Dennis, Chantalle Okondo, Caroline W. Kabiru, and Bettina Shell-Duncan. 2018. "Tracing change in female genital mutilation/cutting: Shifting norms and practices among communities in Narok and Kisii counties, Kenya-Brief," Evidence to End FGM/C: Research to Help Girls and Women Thrive. New York: Population Council. 


\section{TRACING CHANGE IN FEMALE GENITAL MUTILATION/CUTTING: SHIFTING NORMS AND PRACTICES AMONG COMMUNITIES IN NAROK AND KISII COUNTIES, KENYA}

The Evidence to End FGM/C programme consortium generates evidence to inform and influence investments, policies, and programs for ending female genital mutilation/ cutting in different contexts.

Population Council Lead Institution

Africa Coordination Centre for Abandonment of Female Genital Mutilation/Cutting,

Kenya (ACCAF)

Global Research and Advocacy Group, Senegal (GRAG)

MannionDaniels Ltd. (MD)

Population Reference Bureau. (PRB)

University of Washington (Prof. Bettina Shell-Duncan)

University of California, San Diego (Dr. Gerry Mackie)

Funded by

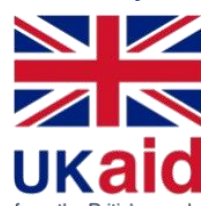

from the British people

\section{INTRODUCTION}

The 2014 Kenya Demographic and Health Survey (KDHS) estimates that 21 percent of girls and women ages 15 to 49 years have undergone female genital mutilation/cutting $(\mathrm{FGM} / \mathrm{C}) .{ }^{1}$ Although the national prevalence of $\mathrm{FGM} / \mathrm{C}$ has steadily declined from 38 percent in 1998 to 21 percent in 2014, the prevalence remains high in some ethnic groups such, as the Somali (94\%), Samburu (87\%), Kisii (85\%), and the Maasai $(78 \%)^{2}$. Figure 1 shows that prevalence of $\mathrm{FGM} / \mathrm{C}$ remain very high among ethnic Somali women, older cohorts of Maasai and Kisii women, but appear to be declining in the youngest age cohorts.

Figure 1: FGM/C prevalence across age-cohorts by ethnicity, KDHS 2014

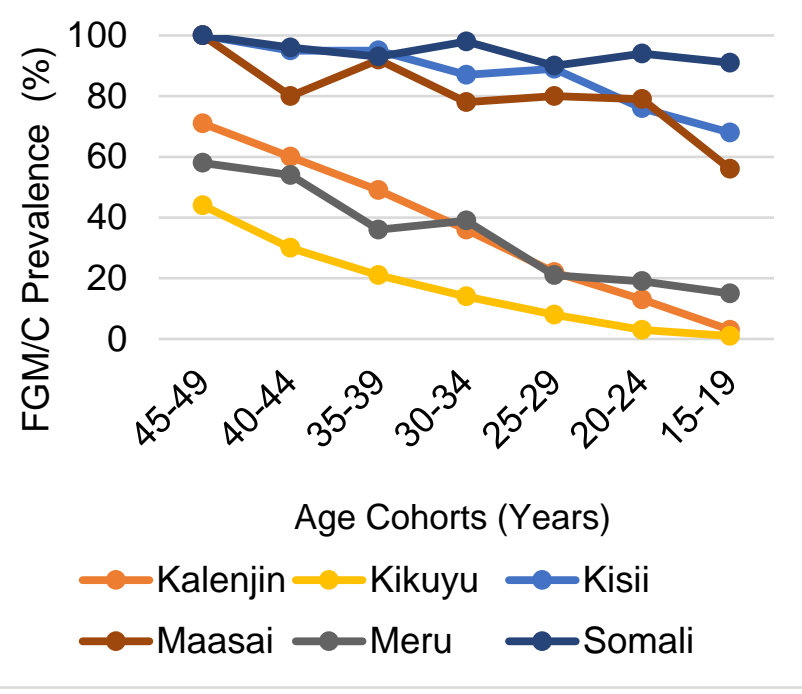

This policy brief summarises key findings from a study $^{3}$ that examined whether there are shifts in norms and practices related to $\mathrm{FGM} / \mathrm{C}$ among communities in Narok (predominantly inhabited by Maasai) and Kisii (predominantly inhabited by Abagusii) counties. Narok county has a high prevalence of cut girls aged 14 years and younger but experienced a declining trend between 2003 and 2014. Kisii County, on the other hand, also has a high prevalence of cut girls aged 14 years and younger but there was no change in prevalence between 2003 and 2014.
Recommendations

Programmatic

- FGM/C programme implementation approaches should involve coordinated group reflections on local values,

aspirations, beliefs, and experiences related to

FGM/C. Engaging community members in values deliberation is likely to facilitate community-wide abandonment.

- Rather than focusing on health risks,

programmes should address human rights issues and gender norms to encourage community members to abandon FGM/C.

- Local grassroots organizations can be effective in changing norms/practices around FGM/C. Sufficient resources should be allocated to them.

- Commitment over the long-term to ensure successful and sustainable change. Programme activities implemented for a short period (for example less than a year) are likely not to bring about the desired behaviour change. 


\section{METHODS}

Data were collected using in-depth interviews, focus group discussions, and observations of interventions. The interviews were conducted with community gate keepers, healthcare workers, government officials, programme implementers, parents/guardians, girls living in the community, and girls living in rescue centres. Group discussions were held with community members. The study also mapped ongoing strategies aimed at addressing $\mathrm{FGM} / \mathrm{C}$ and observed implementation of intervention events by community programmes.

\section{FINDINGS}

\section{How are FGM/C interventions implemented?}

- Programme implementers in both counties use a mix of approaches to encourage $\mathrm{FGM} / \mathrm{C}$ abandonment including: alternative rites of passage, legal measures, intergenerational dialogues, community outreaches, and rescue centres.

- Interventions have focused on raising awareness about the health consequences of $\mathrm{FGM} / \mathrm{C}$ in both counties.

- Interventions that involve coordinated group reflections on local values, aspirations, beliefs, and experiences related to $\mathrm{FGM} / \mathrm{C}$ are uncommon.

\section{What are the changes in FGM/C practices?}

Participants mentioned four key changes in the practice of FGM/C (Figure 2) that are largely driven by increased awareness of the associated health risks and laws banning $\mathrm{FGM} / \mathrm{C}$.

Figure 2: Changes in FGM/C practices

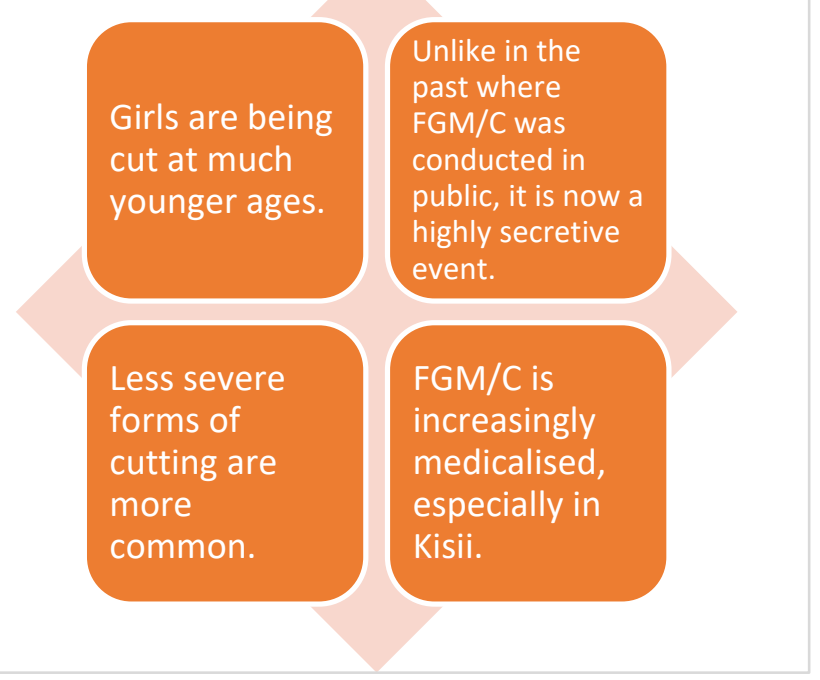

\section{What are the changes in FGM/C-related norms?}

- In both counties, FGM/C is believed to promote sexual restraint, hence upholding morality in the community and fidelity in marriage. Reduced sexual desire, however, is believed to lead to marital instability as men find sex with cut women less sexually satisfying than with uncut women.

- $\mathrm{FGM} / \mathrm{C}$ is widely believed to heighten a girl's chances of being married early. There is, however, ambivalence regarding $\mathrm{FGM} / \mathrm{C}$ being a prerequisite for marriage, especially in Narok, where participants noted that it is increasingly acceptable to marry an uncut woman.

- Emphasis on raising awareness about health risks in FGM/C interventions has increased public knowledge of the harms of $\mathrm{FGM} / \mathrm{C}$. However, knowledge about health consequences of $\mathrm{FGM} / \mathrm{C}$ alone may not lead to abandonment.

- Culture and/or tradition is an important reason why communities continue to practise $\mathrm{FGM} / \mathrm{C}$, more so in Kisii than in Narok.

- While $F G M / C$ is a rite of passage in both communities, for women in Kisii, in particular, FGM/C confers ethnic identity and earns them "respect" from family and community.

\begin{abstract}
"Nowadays, men say that the uncut girls are better in bed than the cut ones, so you find mostly they marry more than one wife or go to towns to look for those who are not circumcised leaving the circumcised woman at home. So, you see this FGM even breaks families."
\end{abstract}

35-year-old female, FGD, Narok

\section{What factors hinder the abandonment of FGM/C?}

- Adherence to culture and tradition, especially in Kisii.

- Negative social sanctions faced by uncut women such as being ostracised and excluded from community activities.

- The hidden practise of $\mathrm{FGM} / \mathrm{C}$ in response to the antiFGM/C law.

- Limited funding for anti-FGM/C programmes, which reduces the reach of these programmes.

\section{CONCLUSION}

Although Kisii and Narok are FGM/C hotspots, practising communities in these counties are reassessing norms and traditions in light of the current social and legal climate. These changes may provide a useful starting point for intervention programmes that seek to create dialogue and critical reflection on the practice of $F G M / C$ in an effort to accelerate its abandonment.

\section{REFERENCES}

1. KNBS, \& ICF International. (2014). Kenya Demographic and Health Survey 2014. Calverton, Maryland.

2. Shell-Duncan, B., Gathara, D., \& Moore, Z. (2017). Female Genital Mutilation/Cutting in Kenya: Is Change Taking Place? Descriptive Statistics from Four Waves of Demographic and Health Surveys. New York: Population Council.

3. Matanda, D, Okondo, C, Kabiru, C. W. and Shell-Duncan, B. (2019). Tracing Change in Female Genital Mutilation/Cutting: Shifting Norms and Practices among Communities in Narok and Kisii Counties, Kenya. Evidence to End FGM/C: Research to Help Girls and Women Thrive. New York: Population Council. 